\title{
School-Based Assessment: A Case Study of a Lower Secondary Schools Music Education in Malaysia
}

Lee Soo Mei @ Jake Lina Lee, Cultural Centre, University of Malaya, 50603 Kuala Lumpur, Malaysia, jakelina@siswa.um.edu.my

and

\section{Loo Fung Ying}

Cultural Centre, University of Malaya, 50603 Kuala Lumpur, Malaysia, loofy@um.edu.my

and

\section{Chua Yan Piaw}

Faculty of Education, University of Malaya, 50603 Kuala Lumpur, Malaysia, chuayp@um.edu.my

(C) 2018 Cultural Centre, University of Malaya. This work is licensed under the terms of the Creative Commons Attribution (CC BY-NC-ND) (https://creativecommons.org/ licenses/by-nc-nd/4.0/)

Received 06 August, 2018; Accepted 11 December, 2018; Published 31 December, 2018.

\begin{abstract}
This study took on a qualitative approach and examined the implementation of Schoolbased Assessment (SBA) in a selected Malaysian lower secondary school focussing on music as subject. SBA or more commonly known in Malay as PBS (Pentaksiran Berasaskan Sekolah) was introduced as an alternative to the exam-oriented learning that has been generally practised in public schools for years. In-depth interviews were conducted to various stakeholders such as teachers, school administrators, officers of Examination Syndicate, officers of Education Department in the state and district, parents and students. The data were obtained from participant observation and general observation, before they were analysed using the ATLAS.ti software. This study aims to draw insight into the implementation of SBA and issues related to the implementation of SBA over the previously exam-centric education system. Findings from this research may serve as a reference to various stakeholders as a mean of suggestion for improvement.
\end{abstract}

Keywords: Music, School-based Assessment, Malaysia, formative assessment.

\section{Introduction}

The idea of SBA (School Based Assessment or Pentaksiran Berasaskan Sekolah) was approved by the Malaysian Ministry of Education in 2006 (Tong, 2014). Its 
implementation in primary schools in 2011 and secondary schools in 2012 aimed at improving teaching and learning practices in the hope of giving lesser emphasis to the traditional exam-centric educational system (Hashim, Aziz, Di, Zakaria, \& Baharun, 2016). The former exam-oriented system was adapted from the British system during colonial period (Tong, 2014), while the new SBA system is a transformation that focuses on formative assessment.

SBA is considered holistic in terms of evaluating the cognitive, affective and psychomotor domains. For secondary schools, it was first implemented among Form One students in 2012. The assessment system was divided into a) academic and b) nonacademic. The academic assessment calls for two assessments: a) School Assessment and b) Central Assessment. On the other hand, the non-academic assessment is comprised of Psychometric Assessment and Assessment of Physical, Sport and CoCurricular Activities.

The evaluation includes a 6-band scale (see Table 1). By using evidence and assessment data, teachers are able to monitor students' achievements throughout the year. Teachers would normally observe students when they are completing assessments and learning tasks in the classroom. Hence, the practise of SBA conforms to the findings of Black, Harrison, Marshall and William (2004) and Black and William (1998) where formative assessment is important in helping to identify weak students and to narrow the gap between high and low achievers.

Table 1

SBA's 6-band scale (Ministry of Education, 2012a)

\begin{tabular}{|c|l|}
\hline Band & \multicolumn{1}{|c|}{ Standard Descriptors } \\
\hline 6 & $\begin{array}{l}\text { Acquire knowledge and skills and apply them creatively in the } \\
\text { musical activities as well as an example to other students and } \\
\text { can demonstrate correctly and accurately with ethical values. }\end{array}$ \\
\hline 5 & $\begin{array}{l}\text { Acquire knowledge and skills and apply them in the musical } \\
\text { activities correctly and accurately and be an example to other } \\
\text { students with ethical values. }\end{array}$ \\
\hline 4 & $\begin{array}{l}\text { Acquire knowledge and skills and apply them in the musical } \\
\text { activities correctly and accurately with ethical values }\end{array}$ \\
\hline 3 & $\begin{array}{l}\text { Acquire knowledge and skills and apply them in the musical } \\
\text { activities with ethical values. }\end{array}$ \\
\hline 2 & $\begin{array}{l}\text { Acquire knowledge and skills and apply them in the musical } \\
\text { activities with ethical values. }\end{array}$ \\
\hline 1 & Knowing basic musical and ethical values. \\
\hline
\end{tabular}




\section{Literature Review}

Reviewing literatures concerning music and learning in Malaysia, a majority of the studies focused on traditional music and learning (Ramona, 2012; Lee, Loo \& Zaharul Lailiddin, 2015; Loo \& Loo, 2016), music and its effect in learning (Lim, Pan \& Chua, 2012; Tam, Chua, \& Loo, 2015; Liow, Affendi \& Loo, 2014), other perspectives in teaching and learning (Abdullah, 1990; Shahanum, 2006; Fong \& Jelas, 2010; Loo, Evens, Mohd Nasir, \& Loo, 2015) and the learning of music in the area of sport (Loo, Loo, \& Chua 2013; Loo \& Loo, 2015; Salle, Aman, Hashim, \& Loo, 2016). Therefore, there is a lack of research looking into the SBA system in music education in Malaysia. However, there were some published press and journal articles on SBA on other school subjects.

Common to the reception of new ideas, psychological resistance over the SBA resulted in a mixed-response published in local newspaper. This caused an upheaval in the much conventional exam-oriented educated Malaysian society and its launch in Secondary school resulted in sensational topics that graced the pages of local dailies. Teachers' complaints over the online system and overloaded workload of uploading students' data was common (Rahman, 2014). The worse among these may be a teachers' rally held in Bangi, Selangor over the extra burden of data submission and the weak online system (Kang and Goon, 2014). In addition, scholars carried out studies on the implementation of SBA in Malaysia found a few issues.

A study by Hamzah and Pamasivam (2009) observed that the oral assessment of English was not in compliance with the guidelines taken from the Ministry of Education. Another study by Chan, Gurnam and Md Rizal (2006) criticises teachers' unfamiliarity with the SBA assessment system. Similarly, a study by Faizah A. Majid (2011) that carried out a survey to 157 primary school teachers and another by Othman, Salleh, and Norani (2013) reveal similar result. Norzila (2013) on the other hand, found that the training model of SBA may have issues of clarity in the dissemination of information. A year later, scholars Talib, Kamsah, Naim, Latif, Abu Naim and Abdul Latif (2014) found similar results where out of the 408 samples they recruited, the informants revealed only a basic level of understanding of the Assessment for Learning (ALF) and asserted that attention must be paid to teachers' competency. Other criticism includes the lack of proper preparation and technological aid (Mohd Farid, 2014). While Chapman and Goon (2014) revealed that a new implementation of Standard Performance Document (SPD) would solve the problem with simplified tools for student monitoring.

The situation mirrored some of the cases in other countries that practise SBA earlier in the history such as United Kingdom, United States of America, Japan, Australia and New Zealand. For example, Black and William (1988) explained that a successful implementation of SBA depends very much on the teachers and the students. Similar to the case in Malaysia, Woods, Baker, and Hopper (2004) found the same situation in the American tertiary education setting where many professors resisted online management tools for student assessment. Indeed, in a survey over 862 faculty staffs, 38 higher institutions resisted using the online course management system. Conversely, a study by Marra and Jonassen (2001) shows that teachers prefer to use technology as an aid to ease their workload but not to monitor student achievement. A more recent 
study by Reyneke (2016) reveals issues and challenges in South African schools and emphasises the validity and reliability of assessments. Reyneke's findings show some similarities to the present case study in terms of teachers' and students' ethics and conduct.

The absence of a valid assessment in SBA and other issues may hamper the effect and essence of conducting formative assessments, which is important in moving towards the educational direction of heutagogy. An emphasis on heutagogy in the pathway to redesign Malaysian education (Rozana, 2017) and relates similar views that emphasise on self-education and competency of technology. Therefore, this paper aims to examine the various issues in the implementation of SBA in music education, and ways to improve the system based on interviews with the various stakeholders and observation.

\section{Methodology}

This study took a qualitative approach to investigate feedbacks from the stakeholders on the impact of SBA and students' achievements in the teaching and learning process. Items in grounded theory were used as directorial questions during the partially structured interviews (see Fig. 1). The purpose was to identify the issues and the obstacles faced by the informants.

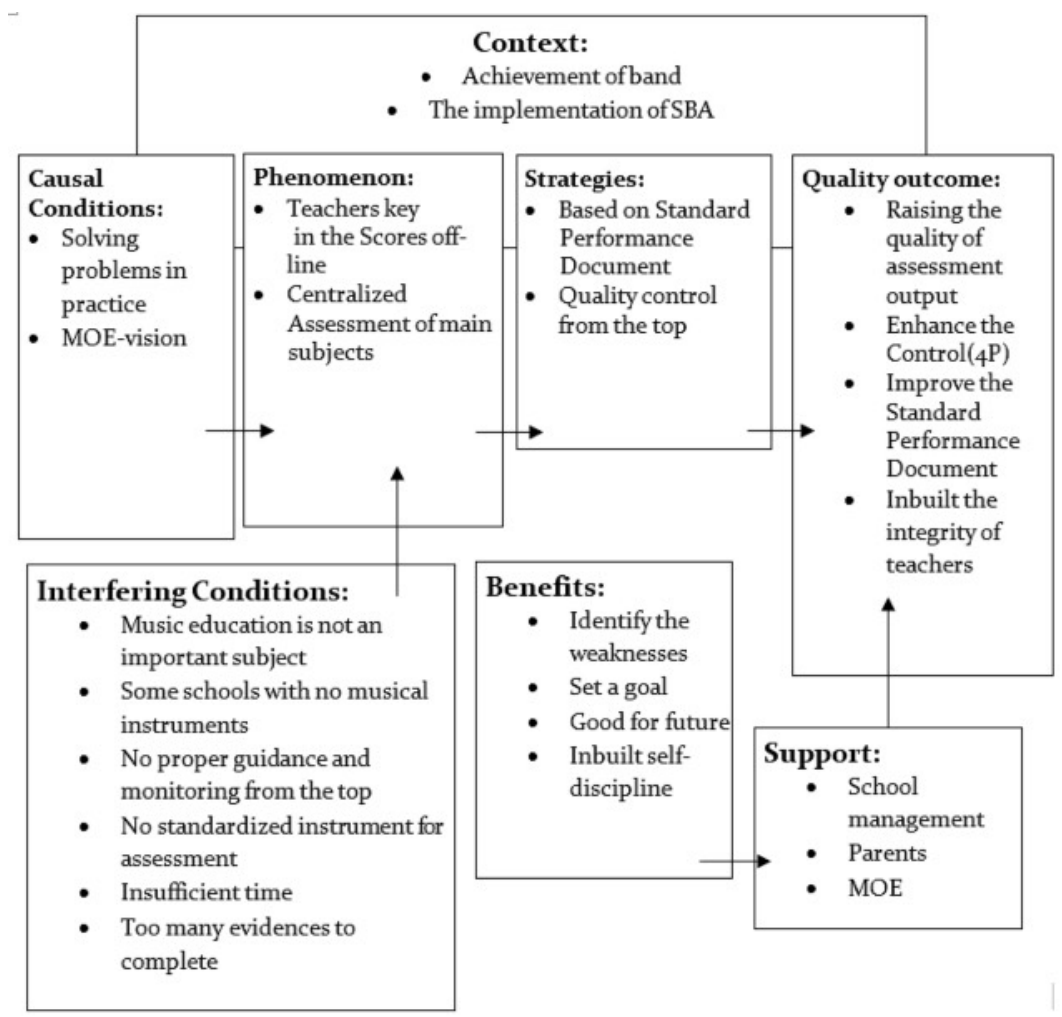

Figure 1. Paradigm diagram of the grounded model for implementation of School Based Assessment (SBA) 
In this research, interview, observation and self-reflexive analyses were the main approaches. Semi-structured interviews were carried out to ten voluntary informants (teachers, school administrator, Malaysian Examinations Syndicate officer, state and district education department officer, parents and students). According to Bogdan and Biklen (1982), qualitative interviews are the principal strategy for data collection aside from document analysis, observation or other techniques (Bogdan and Biklen, 1982). Interviews were supported with the analysis of documents comprising conversation in between interviewers and researcher (Patton, 1990). In this study, each interview session took a duration of approximately twenty-five minutes and the session was recorded with permission from the interviewees.

The interview sessions were transcribed and the informants were labelled as informant A to $\mathrm{J}$ for confidentiality. According to Merriam (2009), transcribing these interviews verbatim provides a comprehensive database to conduct analysis. The data gathered from the interview and observation were coded, and then developed into categories and themes. Participant-observation was carried out by the first author, who is a music teacher at one of the lower secondary schools in Malaysia. A self-reflexive approach added qualitative data via teaching music subject to the first cohort of SBA students for a period of three years. In order to ensure the validity, a triangulation of the data collected from the interviews, participant-observation and self-reflexive account by which the teacher involved in the phenomenon (the first author) was carried out.

\section{Results and Discussion}

The outcome of the analysis via coding of interviews into themes reveals scenarios in the implementation of SBA and the suggestion of new ways of improving the implementation of SBA assessment system. Table 2 presents the criteria of coding according to the framework in Figure 1, while Table 3 is a list of themes generated from both interview and observation.

Table 2

Criteria for Coding

Theme Sub - theme

Casual conditions

Phenomenon

Interfering

Conditions

Strategy

Benefits problem solving, Ministry of Education's vision

manner of implementation, types of assessment

implementation, knowledge, support, teachers' attitude,

skill, musical instruments

acceptance, function, instruments of assessment, subsequent action

detect weaknesses, improve discipline, better future 
Supports

Quality classroom size, training, funding

assessment, integrity, performance

Table 3

Domain Analysis

Data

1. Previous assessment system was too examination oriented.

2. Needed for competitive and independent learning environment. conditions

3. Needed for global challenging.

1. Student central learning.

2. Students have to complete the work by their own.

3. Getting knowledge through many sources.

4. Teachers carry out SBA without record.

5. Increase teachers work load.

1. Music education in an unimportant subject

2. Insufficient of musical instruments.

Interfering

3. Insufficient coaching time for each student.

4. Lack of prior knowledge.

1. Providing relevant training to teachers.

Strategies

2. Changing to off-line record system.

3. Ensure the quality assurance.

1. Identifying the weaknesses and strength of students.

Benefits

2. Creating an e-learning environment.

3. More hard working in practice.

4. Recognising students' ability.

1. Arrangement of the time table by the school management.

2. Encouragement of parents.

Supports

3. Providing teacher helper.

4. Exposure of courses and workshop.

1. Raising the quality of assessment output.

2. Enhancing the quality control.

3. Inbuilt the integrity of teachers.

4. Improve the Standard performance Document.

4.1 Causal Conditions in the Implementation of SBA

During the interview and observation, the informants' feedbacks were positive with regard to the new system, indicating its necessity in meeting global challenges. The new SBA was perceived to focus on developing competent and knowledgeable 
students along with good moral standard, well-being, and capable of creating a harmonious society where the practice of soft skills is more visible than an examoriented education. As such, the implementation of SBA in secondary school serves as an ideal preparation that goes along the emphasis on heutagogy in tertiary education launched by the Ministry of Higher Education in redesigning Malaysian educational system since 2015, which goes along with the fourth industrial revolution.

Data from the informants reveal that the previous education system is too exam-centric and students were 'spoon-fed' to prepare for possible questions that may come out in the exam. For example, a district education officer revealed that the SBA is important because of its formative assessment:

...the concept of SBA, more to student central learning. Teacher is the facilitator and prepares the sources to assess students' achievement based to the requirement of the topic. Before the implementation of SBA, teachers used to spoon feed the students and students were the passive recipient in the teaching and learning process.

In addition, a Malaysian Examinations Syndicate officer claimed that:

One of the good reasons is before this implementation; we were more examination-oriented whereby students will only be evaluated at the end of the term. But by using this system, students are assessed right after every lesson.

SBA allows students a chance to perform in formative assessment where the end result shows feedback from both parties - teachers and students (Sadler, 1989). A parent commented that the importance of independent learning is being emphasised in the new education system:

Yes, it is more to student-centered. In order to achieve the highest band six, he or she must work independently to complete the assignment.

Another informant, a teacher, was positive about the implementation of SBA in Malaysian educational system:

Basically, SBA is indeed a good and systematic evaluation system. This system is a holistic assessment in the evaluation in terms of cognitive; psychomotor affective and consistent with the National Education Philosophy. In addition, formative assessment during the teaching process helps students to improve their learning skill throughout the whole lesson.

Thus, student-centered learning is achieved using the SBA and it is one of the ways in inducing a healthy competition among students to achieve higher band. It aims to produce students who are knowledgeable, competent, have leadership skills and a wellrounded individual.

\subsection{The Phenomenon of SBA}


The implementation of the SBA is aligned with Malaysia Education Blueprint 2013-2015 that consists of six key elements: a) knowledge, b) thinking skills, c) leadership skills, d) bilingual proficiency, e) ethics and spirituality, and f) national identity, which needed to be equipped by each student so that they would be compatible in a global context. This blueprint was no doubt corresponding and was aligned with the National Education Philosophy (Ministry of Education, 2012b). During interviews with students, a majority of students revealed that their way of learning is different and that they were more independent through the SBA system. A student mentioned that:

We need to find the answer through many sources and discussed among our friends. We are just not leaning from our teacher.

A school administrator commented on the changes during an interview that via the SBA, students now have a platform to work on their own ideas:

I think SBA gives a space to students to work on their own. Teacher might give an example on A, and the students can develop the idea to be $\mathrm{B}$ or $\mathrm{C}$. Students have to work on it.

Data from interviews reflect the same as in the first author's teaching experience. SBA triggers initiative for self-learning hence provides space for individual development such as thinking and leadership skills. In this way, students need to be more proactive in gaining knowledge and upgrading their skill through the process of independentlearning.

However, there may be pros and cons for different assessment system, that is formative or summative. During the interview and observation sessions, there is an obvious loophole in the teacher-facilitator approach if the teaching staff is not prepared to deal with students who are not pro-active. Not only that, there may be a danger in the practice of formative assessment in SBA when a teacher's ethics is at stake. For example, a student revealed that:

... the teacher seems to not really bother so even though the students are not really serious in searching the source for the portfolio he or she can still get a good grade.

In addition, local press reported that parents voiced out their concern over the transparency of the overall system (The Star, 2014). This scenario calls for an attention that the ethical conduct of both teachers and students are of high importance when it comes to formative assessment and independent-learning. Besides, the lack of continuity and record is a matter of concern in the practice of SBA. During an interview, a school administrator revealed that:

I do agree with the SBA procedure where after each lesson, there would be an assessment. However, at the same time, I think whatever knowledge that the students have learned or had been assessed should be reinforced and evaluated following a certain standard.

Another teacher commented that: 
Currently, I teach according to the syllabus with SBA in mind and the SBA is done after each lesson verbally without record. The record is intended to be done when a former SBA is done on paper.

Via interview and observation, apparently, the SBA and its aims have yet to be fully achieved. This may be due to the fact that SBA is still at an unripen age of implementation, and that the situation may improve when both teachers and students are more prepared at gauging the new teaching and learning approach along with better tools in monitoring.

\subsection{Interfering conditions in SBA}

In this study, the analysis shows that interfering conditions is one of the important factors that may need attention in the implementation of SBA. In order to carry out the reformation of the new SBA in the educational system in Malaysian primary and secondary school, various challenges such as ensuring the quality of the teaching party, disciplinary issues in students, equipment and facilities, more effective and innovative delivery methods need to be considered to conform to the current requirements at the schools. However, there were obstacles and among these, the informants pointed that one of the main interfering conditions is that the perception of music education as a subject is of no importance compared to mathematics and science, for example. The centralised assessment set by the Examination Syndicate of Malaysia only focused on the main subjects such as Science, Mathematics, Malay language, English language, and Islamic Education. Therefore, music education is deemed unimportant by students. A school administrator explained that:

It is an evaluation based on 6 bands and it is only evaluated in the school level but not in the Central Evaluation. In my point of view, in the PT3 it should be evaluated like other subjects which to be carried out in the central assessment.

Thus, during another interview, a state education department officer explained that "Therefore, music education was treated as an unimportant subject and the teaching hour is lesser if compared with other countries."

Resources are also another issue as informant $\mathrm{D}$ pointed out that the insufficient musical instruments provided at school affects students' achievement especially in achieving the top band, which is Band 6 (see Table 1). In some schools, students were not provided with sufficient musical instruments for practice. The solution that students would be taking turn to practice, and therefore, share an instrument was not timeeffective. Even the limited fund allocated for the music panel shows that this subject has less importance in the national education.

Another interfering condition would be the design of the 105-evidence-based assessment to be monitored by the teachers. The informants revealed that they have problems dealing with the monitoring system where the 105-evidence-based assessment is both time-consuming and impossible when there is a large number of a student in the classroom. This also resulted in students that were not allowed to proceed to the higher band as they failed to complete the required evidences in the 
lower band as stated in the Standard Performance Document. A teacher explained during an interview that:

If we look at the contact hours in the secondary school, it has only five periods, nevertheless with the large number of students in a class, it is quite hard for a teacher to give a personal coaching to each of them.

In addition, a district education officer confirmed that "[w]e must admit that SBA adds on teachers' workload." All informants agreed to the situation and the first author's personal experience conforms to the scenario. The approach of the 105-evidence-based assessment is indeed time-consuming and burdens the teaching staffs especially when they are required to prepare several instruments to be used in the assessment. Teachers were required to note down the students' achievements right after the lesson and to submit students' performance data online.

Another interfering condition may be the lack of students' interest in the subject itself. A teacher explained that:

In my opinion this SBA should be repealed in music education since the implementation is not effective. Most students in my school are not interested in this subject. They were forced to learn the subject...

Informant $\mathrm{G}$ revealed that a majority of her students does not show interest in learning this subject. Thus, these interfering conditions were found in the implementation of SBA in music subject and their presence should not be overlooked by the stakeholders.

\subsection{Strategies for Improvement}

Since the implementation of SBA, issues stated in Section 4.2 and 4.3 were observed and new approaches were taken such as the new Guidelines of Student Development, formation of Quality Assurance Policy, Monitoring Committees, and suggestions of more training workshops. A teacher revealed that:

Since April 2014, the implementation of the SBA has become easier and less of a burden for the teachers. The performance standard document has been replaced by the Guidelines of student development. Teachers no longer need to record the achievement of students online. The offline recording of students' achievement makes the implementation of SBA more flexible and easier for teachers.

Another informant mentioned that the quality assurance is important in ensuring that the SBA is carried out accordingly:

In schools, the Head of Department and Head of Panel are the persons who are responsible in monitoring the implementation of SBA for every subject. The principal is the person in-charge of the mentoring and monitoring. The SBA report must be verified by principal. 
When the question "What was the most important strategy in the quality control of SBA?" was given to the interviewee, a Malaysian Examinations Syndicate officer answered:

\begin{abstract}
Yes, there is a quality control which we address it as 4P. There are Pemantauan [monitoring], Penyelarasan [coordinating], Pementoran [mentoring] and Pengesanan [identifying]. This is the system which is practised in SBA to ensure the reliability and validity of the assessment as a whole. There must be an experience and knowledgeable teacher as the mentor to advice the other teachers about the content of the curriculum.
\end{abstract}

Another informant, a school administrator explained that "[e]very school has to form an SBA committee for every subject to assure the implementation of SBA is always on the right track." Besides quality assurance, when asked about the other strategies executed in SBA, the informants were highly concerned about the training and competency. During the interviews, three teachers revealed their opinions as:

I think the best strategy to enhance this system would be to provide teachers with more relevant training, long before the implementation of the system.

Teachers are also expecting to have more exposure and attend courses which related to the SBA.

Teachers need to be proactive in implementing the SBA system. Therefore, teachers should be prepared in a variety of aspects, such as interest, attitude, skills and knowledge.

In summary, the strategies taken in ensuring the success of the SBA implementation ranged from quality assurance and the proposal of more training, where the latter is from the teachers' perspective. From the data collected, it is clear that the Syndicate of Examination has set a quality assurance tool in carrying out the SBA using four levels of quality control. The enforcement from schools, district level and state level play an important role to assure the implementation of SBA is always on the right track.

\title{
4.5 Support from the Ministry of Education
}

Via observation and interviews, informants showed that various supports are still needed in implementing the SBA in Music Education, especially in identifying the weaknesses of students through their performances and abilities in playing music. Based on the excerpts from the interviews with informants, the analysis shows that the supports from the school management and the parents are important in assuring the effectiveness of carrying out the SBA. More support from the Ministry of Education is needed as majority of the teachers stated:

Support is needed from MoE [Ministry of Education] in terms of providing teachers with more help in the class as it is impossible for a teacher to assist all students, especially in a class with a great number of students. 
... provide enough musical instruments as stated in the music curriculum.

Teachers need to improve knowledge in pedagogy in order to know how to attract students.

During the interview sessions, some teachers stressed that certain consideration must be taken into account to improve the SBA system. For example,

School management, the arrangement of the practical music lesson in the afternoon should be on the different day from the curricular activities.

The ideal number of students in the classes is appropriate in the range of 15 to 20 students in order to have better class control and implement the SBA more effectively.

The above statements are made by the informants who expressed their woes and suggestions based on their experience of teaching using the SBA system. According to the teachers, they need support from the Ministry of Education in order to tackle these issues. Training and aids in teaching are important measures that the teachers hope to receive from the ministry in order to improve the new practices of the SBA system.

\subsection{Benefit of SBA}

Informants reported that there are many benefits in implementing the SBA, especially in the context of Malaysian music educational program. From the account given by the informants, it appears that the benefits gathered by implementing SBA may outweigh its obstacle in the future. Via interviews and observation, the data collected during the study clearly show the strength of SBA in identifying students' strengths and weaknesses right from the very beginning of the learning phase, while this was not possible with the conventional summative assessment. Students' ability in playing music is evaluated in every lesson using formative approaches. The accounts given by the informants conform to the benefits of SBA and the growth of independent-learning:

...identify the weak students through the SBA and give them proper guidance immediately (Teacher).

In SBA they know where they are, unlike the examination, they have to wait until the year end then only they know their position in the class. Yes, because students have to find the answers by their own. They can't lean on the teacher but they have to work it out through any sources like Google. (School administrator)

...students are involved in the learning process through negotiations and discussion based on students' strengths and weaknesses. Yes, students are responsible on their learning process, which involve the student directly in discovering knowledge, the use of challenging existing knowledge and deep understanding of new concepts. Giving students freedom to make their own decision to choose about the resources and educational activities. (State education department officer) 
While discussing the benefits of the SBA, the informants highlighted the pressing need of creating an e-learning environment in order to offer students the ability to share materials such as word documents, videos and slides. At the moment, students are working on e-learning asynchronously to, and outside of the classroom setting. The informants also added that by implementing the SBA, students may be more compatible in a global context as they are trained with independent-learning, teamwork spirit, leadership skills, problem solving skills and a discipline of aiming at a higher band achievement without depending only on the teacher's guidance. Thus, a State education department officer was positive that:

SBA gives an opportunity for students to recognise their abilities and strive to improve it.

Along the same line, other informants stated that:

...they are more focus and committed in their study. They have to be alert and stand by because they will be tested at the end of the lesson. (Parent)

...students need to be more focus in class. If the teacher be able to tackle the students, the students will be harder working to achieve what the teacher wants. (District education officer)

SBA produces students who dare to try, have the courage to give an opinion and are able to highlight interests and strive to achieve the highest band in the assessment. (Parent)

Therefore, the benefits gathered from SBA and its implementation is aligned with the Malaysia Education Blueprint 2013-2015. The phenomenon reveals that the absence of summative assessment allows the increased frequency of formative assessment and a more active learning and problem-solving environment that is continuous throughout the year. A self-directed aim towards the achievement of a higher band after every lesson cultivated from the SBA system also avoid students to rely solely on the teacher and their achievements are not merely on examination basis.

\subsection{Quality Assurance}

In terms of quality assurance, according to an earlier paper (see Lee, Loo \& Chua, In Press), the achievement of the students where a majority of $46 \%$ achieved band 4 and only $0.01 \%$ reached band 6 , revealed that there is still room for improvement in the implementation of SBA. The study showed that teachers' integrity is the most important factor in the implementation of SBA. Since the launching of SBA, various strategies had been made such as raising the quality of the assessment output, preserving integrity among teachers, refining the Standard Performance Documents, and upgrading the equipment as well as the facilities to meet the current requirements of schools. Informants raised concern over the integrity and practice of different assessment system:

It is because the SBA itself is based on the curriculum but the implementation and the success of it depends a lot on the integrity of the 
teachers, the support of the school, parents and most importantly is Ministry of Education. (Teacher)

In my view it is not appropriate for the teacher to determine their own methods. The examination Syndicate shall decide a standardised method for the whole country. (Parent)

It is important so that the teachers don't key in the score blindly. We want the result which is able to reveal the ability of the students. (District education officer)

Yes, but the condition is that the students must carry out the assessment honestly. What I mean that there is no copying, cheating or taking people work. (Parent)

The data-rich monitoring system and issues raised by teachers such as the limitation of time over a large classroom size, the availability of music instruments, and the 105evidence-based assessment (see Section 4.3) along with problems of an unprepared or untrained teacher-facilitator (see Section 4.2) are the main factors in causing risks to quality assurance. Besides, the integrity of teachers in assessing is yet to be measurable with the current tools and quality monitoring system available. Thus, transparency in the assessment and monitoring process of the SBA system in teaching and learning requires immediate attention. This probably may call for the presence of an audit committee in assuring the quality of SBA and its conduct.

\section{Conclusion}

The implementation of SBA at a Malaysian lower secondary school was investigated on a naturalistic inquiry basis for a timeline of three years since its implementation by focusing on the music subject. The data gathered from the first author's immersion and participant-observation within the research environment as a school teacher, along with co-researcher's observation and interviews present the outcome of the study that highlight some issues over the implementation of SBA in music subject. This is based on the researcher's immersion within the research environment as a school teacher.

The study shows that the implementation of SBA in the music subject revealed a mixed opinion from various stakeholders. Although the strength in formative assessment enables students to practice independent-learning, problem solving skills, perform and be evaluated at every class, however, there are still issues to be considered in the music subject. These issues include a concern raised over the resources required to run the music subject, classroom size, evaluation system and ethics. The results gathered from this qualitative data analysis may be a reference to the various stakeholders such as teachers and the ministry of education in the decision-making process.

The data collected clearly reflect the Ministry of Education's vision in solving the situation where the education system was too exam-oriented and that students were not trained to meet the new education system that geared towards heutagogy in their future. Results from the study also show that some stakeholders and the students were not prepared in facing the new implementation of SBA. There were still complaints, despite the slow online system for monitoring had been solved, but the assessment 
method that employs a 105-evidence-based evaluation is still questionable in terms of its practicability. Although the Quality Assurance guidelines provided by the Ministry of Education consists of systematic monitoring, mentoring, standardisation and detection measures, however, the reliability of teachers carrying out a formative assessment at every session over a large classroom size may invite question of its validity. Thus, the SBA committee at school plays an important role, and not only that, these issues must be attended and solved.

In conclusion, the implementation of SBA in Malaysia is still at the accountability testing and assessment period. Therefore, the issues raised must be tackled and discussed. Undoubtedly, the integrity of the teaching staffs is of importance in meeting the requirements of Standard Performance Document. Further studies may be required to examine the Standard Performance Document, teaching approaches, and reducing the number of tools for assessment. Still, the study has proven that despite the negative connotations given by the stakeholders, still, there were positive feedbacks in supporting the implementation of SBA.

\section{References}

Abdullah, J. (1990). Music education in Malaysia: An overview. The Quarterly Journal of Music Teaching and Learning, 1(4), 44-53.

Black, P., Harrison, C., Lee, C., Marshall, B., \& Wiliam, D. (2004). Working inside the black box: Assessment for learning in the classroom. Phi Delta Kappan, 86(1), 9-21.

Black, P., \& Wiliam, D. (1998). Inside the black box: Raising standards through classroom assessment. Phi Delta Kappan, 80(2), 139-148.

Bogdan, R., \& Biklen, S. K. (1982). Qualitative research for education. London: Continuum.

Chan, Y. F., Gurnam, K.S., \& Md Rizal Md Yunus. (2006). The Knowledge and Best Practices of Secondary ESL Teachers in School-Based Assessment. Shah Alam: Universiti Teknologi Mara Press.

Chapman, K. \& Goon, J. (2014). Problems being resolved. The Star Online. 23 March. Retrieved 2 April 2014 from http://www.thestar.com.my/news/education/ 2014/03/23/being-resolved/

Kang, S. \& Goon, J. (2014). Teachers show up at rally. The Star Online (23 February). Retrieved 19 May 2016 from: https://www.thestar.com.my/news/nation/ 2014/02/23/teachers-show-up-at-rally-group-joins-protest-against-pbs/

Faizah A. Majid (2011). School -based Assessment in Malaysian Schools: The concerns of the English Teachers. Journal of US-China Education Review, $8(10), 393-401$. 
Fong, C. E., \& Jelas, Z. M. (2010). Music education for children with autism in Malaysia. Procedia-Social and Behavioral Sciences, 9, 70-75.

Hamzah, M.O. and Paramasivam, S. (2009). Between the Ideal and Reality: Teachers' Perception of the Implementation of School-Based Oral English Assessment. The English Teacher, 38, 3-30.

Hashim, Z., Aziz, A. D. A., Di, S., Zakaria, A. R., \& Baharun, H. (2016). School-Based Assessment implementation: The primary school teachers' voices. In Gaol, F. L., Hutagalung, F., Bagautdinova, N., \& Safiullin, L. (Eds.), Social Sciences and Interdisciplinary Behavior: The 4th International Congress on Interdisciplinary Behavior and Social Science (ICIBSoS 2015) (p. 393). Kazan: CRC Press.

Lee, S. M., Loo, F.Y., \& bin Saidon, Z. L. (2015). Team-building in the 24 Seasons Drums Education: From Physical Exercise to Music. Procedia-Social and Behavioral Sciences, 174, 2331-2334.

Lee, S. M., Loo, F.Y., \& Chua, Y.P. (In Press.). Music Teachers' Perceptions of the Implementation of School-Based Assessment in Music Education in Lower Secondary Schools in Malaysia. Tirai Panggung, In Press.

Liow, B. T., Affendi, H. R., \& Loo, F. Y. (2014). Raising Interest with Software Integration in Music Notation Learning. Procedia-Social and Behavioral Sciences, 143, 379-383.

Lim, Z. C., Pan, K. C. \& Chua, Y. P. (2012). A Relationship Between Creativity and Musical Achievement: A survey of music major trainee teachers in a teacher education institution. Malaysian Music Journal, 1(2), 59-71.

Loo, F.Y., Evens, G. I., Mohd Nasir, H. \& Loo, F. C. (2015). Tension Release in Piano Playing: Teaching Alexander Technique to Undergraduate Piano Majors. Procedia-Social and Behavioral Sciences, 174, 2413-2417.

Loo, F.Y., \& Loo, F. C. (2016). Dramatizing 1Malaysia in Contemporary Chinese Lion Dance. Asian Theatre Journal, 33(1), 130-150.

Loo, F.C. \& Loo, F.Y. (2015). Visual perception of phrasing in a tai chi routine using different music accompaniments. Procedia-Social and Behavioral Sciences, 174, 3044-3048.

Loo, F.C., Loo, F.Y. \& Chua, Y. P. (2013). Perception of Congruence between Music and Movement in a Rhythmic Gymnastics Routine. Journal of Basic and Applied Scientific Research, 3(11), 259-268

Marra, R.M., \& Jonassen, D.H. (2001). Limitations of online courses for supporting constructive learning. The Quarterly Review of Distance Education, 2(4), 303-317.

Merriam, S. B. (2009). Qualitative research: A guide to design and implementation. San Francisco, CA: Jossey-Bass. 
Ministry of Education. (2012a). Dokumen Standard Prestasi [Standard Performance Document]. Kuala Lumpur: Examination Syndicate, Ministry of Education, Malaysia.

Ministry of Education. (2012b). Preliminary report: Malaysia education blueprint 2013-2025. Kuala Lumpur: Ministry of Education, Malaysia.

Mohd Farid, M. S. (2014). Dilemma of school-based assessment. The Star Online (18 February). Retrieved 19 May 2016 from: https://www.thestar.com.my/opinion/ columnists/ikim-views/2014/02/18/dilemma-of-schoolbased-assessment/

Norzila M.Y. (2013). School-based Assessment: Transformation in Educational Assessment in Malaysia. Cambridge Horizons (3 June). Retrieved 19 May 2016 from: http://www.cambridge assessment .org.uk/images/139719-sbaseminar-papers.pdf.

Othman, I., Salleh, N. M., \& Norani, N. A. M. (2013). The implementation of schoolbased assessment in primary school standard curriculum. International Journal of Education and Research, 1(7), 1-10.

Patton, M. Q. (1990). Qualitative Evaluation and Research Methods (2nd ed.). Newbury, CA: Sage Publications, Inc.

Rahman, D. (2014). A Change of Emphasis. The Star Online. 18 September. Retrieved 19 September 2014 from http://www.thestar.com.my/opinion/online-exclusive/ whats-your-status/2014/09/18/a-change-of-emphasis/

Ramona, T. (2012). Traditional Music and Music Education in Malaysia: An Overview. Shah Alam: University Publication Centre.

Reyneke, M. (2016). School-based assessment in English language teaching: weighing the cow will not fatten it. Per Linguam: a Journal of Language Learning, 32(2), 1-14.

Rozana, Sani. (2017). Tertiary Education Redesigned. New Straits Times. January 21. Retrieved from https://www.nst.com.my/news/2017/03/206101/tertiaryeducation-redesigned

Sadler, D. R. (1989). Formative Assessment and the Design of Instructional Systems. Instructional Science, 18(2), 110-44.

Salle, D. D., Aman, M. S., Hashim, M. N., \& Loo, F. Y. (2016). Physical Activity and Music on Body Composition, Fitness and Metabolic Parameters Among Obese Singapore Women. International Journal of Exercise Science: Conference Proceedings, 8(4), 76.

Shahanum, M. S. (2006). Popular music in Malaysia: Education from the outside. International Journal of Music Education, 24(2), 132-139.

Talib, R., Kamsah, M. K., Naim, H. A., Latif, A. A., Abu Naim, H., \& Abdul Latif, A. (2014). From principle to practice: Assessment for learning in Malaysian 
school-based assessment classroom. International Journal of Social Sciences and Education, 4, 850-857.

Tam, J. E., Chua, Y. P. \& Loo, F. Y. (2015). The Effect of Rhythmic Pattern in Recalling 10 Digit Numbers. Procedia-Social and Behavioral Sciences, 185, 400-404.

The Star Online (2014). Parents Unhappy with System's Lack of Transparency. Retrieved 19 May 2016 from: http://www.thestar.com.my/news/nation/ 2014/02/14/parents-unhappy-with-systems-lack-of-transparency/

Tong, J. (2014). Education Dilemma in Malaysia. Singapore: Partridge.

Woods, R., Baker, J. D., \& Hopper, D. (2004). Hybrid structures: Faculty use and perception of web-based courseware as a supplement to face-to-face instruction. The Internet and Higher Education, 7(4), 281-297. 